\title{
Morphological characterization by scanning electron microscopy of WC powder particles coated with $\mathrm{Cu}$
}

\author{
J.B. Puga*, C.M. Fernandes***, M.T. Vieira** and A.M.R. Senos* \\ *Department of Materials and Ceramics Engineering, CICECO, University of Aveiro, 3810-193 Aveiro, \\ Portugal \\ **CEMUC-Mechanical Engineering Department, University of Coimbra, Rua Luís Reis Santos, Pinhal de \\ Marrocos, 3030-788 Coimbra, Portugal
}

Cemented tungsten carbides (WC), are considered one of the oldest, most successful and commercialized powder metallurgy products [1]. These materials are commonly composites of WC powder particles bonded with transition metals such as Co or Ni via liquid-phase sintering. WC-based composites have been used for decades in wide engineering applications, as cutting tools, components for oil and gas drilling, metal forming, among others [2]. The conventional processing of the WC based composites initializes with powder preparation, performed by wet milling of all the powder components (WC and metallic binders) [2]. However, this process is high energy consuming, ecologically unfriendly and longstanding, thus new powder processing methods are welcome. In this work, copper $(\mathrm{Cu})$ was selected as an alternative binder, due to its inability to form brittle carbides with WC at higher temperature, the superior ductility (compared with the traditional Co binder) and corrosion resistance. Nevertheless, melted $\mathrm{Cu}$ has low wettability on the WC surfaces, limiting the attained sintered density and, consequently, the final properties. Powder coating techniques, such as high energy ball milling (HEBM) and the sputter-coating technique (ST), improve the binder homogeneous distribution and nanostructuring enhancing the sinterability. WC-Cu composite powders (with $2 \mathrm{wt} . \% \mathrm{Cu}$ ) were prepared using the two methods mentioned above. The morphology of the particles was evaluated by scanning electron microscopy (SEM- Hitachi SU-70) and the distribution and chemical composition were assessed by energy dispersive spectroscopy (EDS- Bruker QUANTAX 400).

The starting WC powder has an average grain size of $9 \mu \mathrm{m}$, as depicted in Figures 1-a) and 2-a). In the WC coating by HEBM, the collisions of ball-to-ball and ball-to-wall with the entrapped powder particles cause at the same time severe binder plastic deformation and $\mathrm{WC}$ fragmentation, endorsing a high uniform distribution of $\mathrm{Cu}$ around WC particles, as is depicted in Figures 1-b) and c). On the other hand, the composite powders prepared by ST revealed a high uniformity of $\mathrm{Cu}$ coating on the WC particles (Figures 2-b) and c)), together with a columnar binder nanostructure, commonly observed on sputter-coated surfaces [5]. In spite of the low binder content, the WC particles seem well covered, taking its rough morphology, in Figure 2-c), and the X-ray maps and the $\mathrm{Cu}, \mathrm{W}$ concentration profiles presented in Figure 3. It can be, therefore, concluded that both powder coating techniques allow high uniform distribution of $\mathrm{Cu}$ coatings on WC particles and, furthermore, the ST technique presents a clear nanometric binder structure. The effect of the coating technique on the sinterability of WC-Cu powders will be evaluated on forthcoming studies.

\section{References}

1. Maximenko A. et al. In: eds. IOS Press, 105, 2001.

2. Fernandes C.M. et al., Surf. Coatings Tech., 206:4915-21, 2012.

3. Yusoff M. et al., Mater. Des., 32:3293-98, 2011.

4. Fernandes C.M. et al., Surf. Coatings Techn., 176:103- 108, 2003.

5. Fernandes C.M. et al., Microscopy and Microanalysis, 14:39 - 40, 2008. 

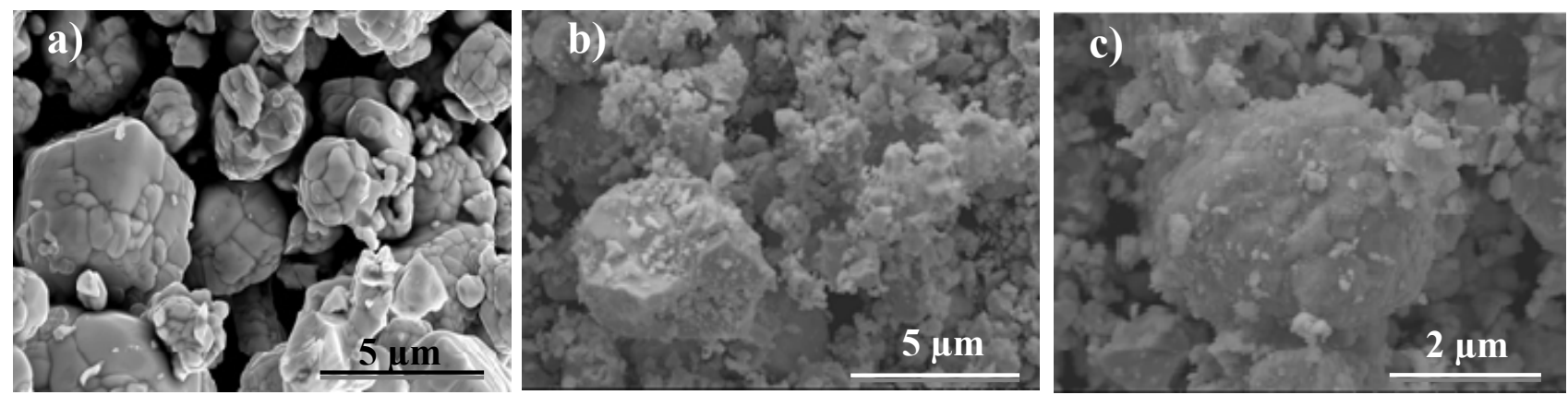

Figure 1. SEM microstructures: a) WC powder particles; b and c) WC-Cu composite powders prepared by HEBM.
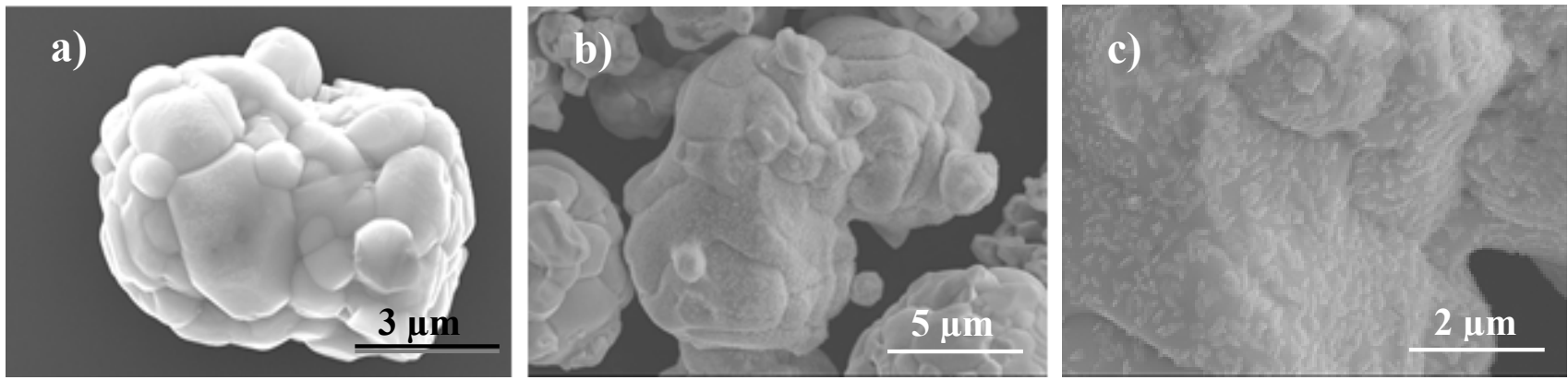

Figure 2. SEM microstructures: a) WC powder particle; b and c) WC-Cu composite powders prepared by ST.
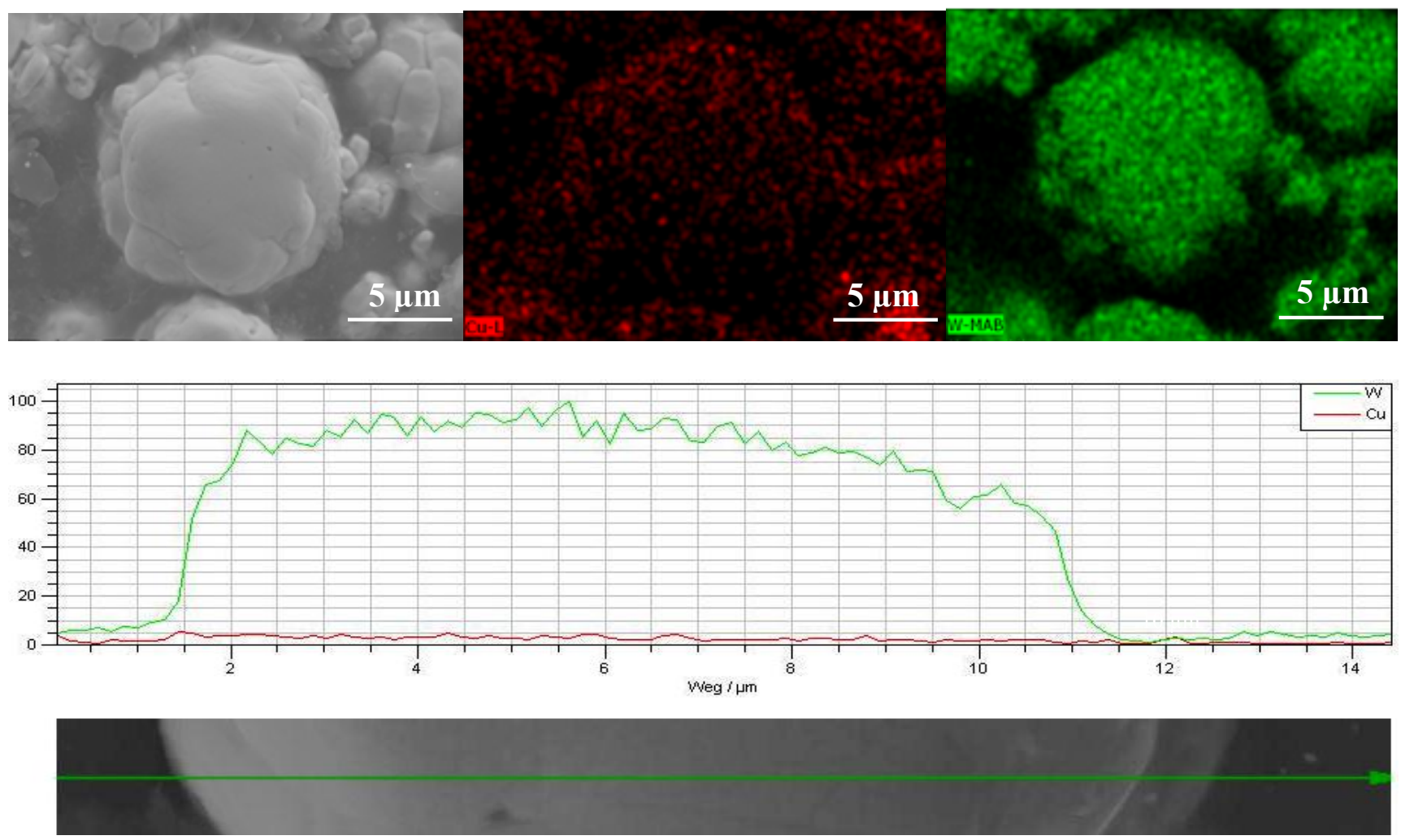

Figure 3. X-ray maps and EDS concentration profiles of the composite powder prepared by ST. 